\title{
WHY PEOPLE BLOG: AN EXPECTANCY THEORY ANALYSIS
}

\author{
Su-Houn Liu, Chung Yuan Christian University, vandy@mis.cycu.edu.tw \\ Hsiu-Li Liao, Chung Yuan Christian University, wenlly.liao@msa.hinet.net \\ Yuan-Tai Zeng, Chung Yuan Christian University, idr1980@yahoo.com.tw
}

\begin{abstract}
The evolution of Internet offers new tools allowing ordinary people to become content creators. One of the latest popular tools is the Internet-based blog. Few previous studies explored and examined user motivations of blogging. In this study, expectancy theory is applied to construct a conceptual framework as well as a measurable model on bloggers' motivation to blogging. Expert interviews and survey instrument were used in this study. Interviews with bloggers were first performed to verify the questionnaire items of the attractiveness of possible outcomes resulting from blogging. After the construction of the questionnaire, a survey was conducted and 177 bloggers were asked to respond the questionnaire. From the 10 motivations examined in this study, bloggers ranked pouring out feelings and connecting with people respectively, as their two most valued rewards. They also assigned the highest probabilities to these rewards. The collected data shows that bloggers with high (both intrinsic and extrinsic) motivation for rewards have higher level of blogging intention. A blogger with higher blogging intention is willing to take more time to maintain their blog and post more articles on the blog.
\end{abstract}

Keywords: Expectancy Theory, Blog, Bloggers

\section{INTRODUCTION}

There are ways to get around the hard sell and promote your message. One of the latest techniques is the blog or weblog [1]. A blog is defined in Wikipedia (wikipedia.com) as a Web site where journal entries are shown in reverse chronological order and usually provide access to their archives, and a way to post comments [14]. News feed formats such as RSS are often provided on blogs. Bloggers are urged to describe their lives, provide commentary and opinions, express their emotions, present ideas through writing, and maintain community forums [4].

Low entry costs make blogging accessible to individual, and a basic blog is easy to establish and to update, requiring no special technical skills [9]. Technorati (http://www.technorati.com/) indicates that there are now 73 million blogs, growing at a rate of 175,000 blogs and 1.6 million postings daily [16]. According to research firm PO Media LLC, Ad, the spending on blogs, podcasts and web feeds is expected to jump $145 \%$, to about US $\$ 50$ million in 2006. Blogging is expected to account for US $\$ 36.2$ million in 2006 [1]. Because of their popularities, blogs are now being recognized as a new kind of news media. But unlike traditional news media which were dominated by news agency and professional reporters, blogs are operated by millions of ordinary people. So the prosperity of blogging brings in an interesting question: Why would those people like to devote themselves on building and operating their individual blogs?

The research objective of this study was to examine the motivational factors of the bloggers and the relationship between their motivations and their intention and conducts of blogging. Few previous studies explored and examined user motivations of blogging. Nardi, Shiano, Gumbrecht and Swartz [4] discovered five major motivations for blogging with indepth interviews: documenting one's life; providing commentary and opinions; expressing deeply felt emotions; articulating ideas through writing; and forming and maintaining community forums. In this study, expectancy theory [18] is applied to construct a conceptual framework as well as a measurable model on the motivation of the bloggers. The model can then be used to provide a better understanding on the bloggers' behavioral intention and conducts.

\section{LITERATURE REVIEW}

Expectancy theory has been recognized as one of the most widespread attention of individual motivation [10]. Based on Vroom [18] research, expectancy theory indicates that overall Motivation (M) of a user to blogging is the summation of the products of the attractiveness or importance of various individual outcomes associated with blog $\left(\mathrm{A}_{\mathrm{k}}\right)$ and the probability that blog will produce those outcomes $\left(\mathrm{I}_{\mathrm{k}}\right)$, which is expressed by the equation:

$$
M=\sum_{\mathrm{k}=1}^{\mathrm{n}}\left(\mathrm{A}_{k} \times \mathrm{I}_{k}\right)
$$

Where M=motivation for blogging; $A_{k}=$ attractiveness (or importance) of outcome k related to blogging, and $\mathrm{I}_{\mathrm{k}}=$ the perceived probability that being productive in blogging will lead to outcome $\mathrm{k}$. 
In this study, bloggers were asked to evaluate the attractiveness of 10 possible outcomes (the rewards) resulting from bloging. According to the expectancy theory, multiplying the attractiveness of each outcome by the probability of its occurrence and then adding the resulting products yields total motivation of individual blogger to blogging. According to the systematic analysis, the bloggers then determined how much effort they would like to make according to their total motivation scores.

Previous researchers have indicated that expectancy theory can support an appropriate theoretical framework to measure users' intention to use an information system [5, 17, 19]. However, empirical research applying expectancy theory to blogging behavior has been limited. Some work reported that user involvement is associated with user intention of an information system [7, 13]. It is expected that bloggers' intention of blogging is positively related to the degree of their bolgging conduct. The hypotheses are formulated as below to address the bloggers' behavior:

$\mathrm{H1}$ : Blogging motivation is positive related to the blogging intention.

$\mathrm{H} 2$ : Blogger's intention is positive related to the degree of blogging conduct.

\section{The Research Model}

Figure 1 represents the proposed research model drawn from the constructs of blogging motivation, blogging intention, and blogging conduct as discussed above. The research model is empirically tested in this study. In this model, blogging motivation comprise of both the extrinsic motivations and the intrinsic motivations.

\section{<insert Figure 1 here $>$ \\ <insert Table 1 here> \\ METHODOLOGY}

Expert interviews and survey instrument were used in this study. Interviews with the 5 bloggers were performed to generate the questionnaire items for 10 possible attractive outcomes (Rewards) resulting from blogging, including 5 extrinsic motivation and 5 intrinsic motivation. The attractiveness was evaluated by using a scale of 1 to 10 , with 10 being "strongly agree" and 1 being "strongly disagree". The probability that blogging will impact on those rewards was also examined by a scale of 1 to 10 , with 10 being "To a great extent" and 1 being "Not to a great extent". The intention of blogging was assessed using three items constructed following the recommendations of Davis et al. [8] and one additional item (4. I intend to recommend others to conduct their blogs) was added according to the unique network connected feature of the blogging. Respondents scored on a seven-point Likert-type scale with the end points being "strongly disagree" and "strongly agree". Furthermore, the conduct of blogging was indicated by the number of articles post by the bloggers and their times spent on operating the blog.

The bloggers who conducted blogs on the WRETCH website (http://www.wretch.cc) were asked by the researchers to respond the questionnaire of this study. The WRETCH website is the most famous and well established blog platform currently in Taiwan. From the 400 survey questionnaires we have distributed, 177 were returned and usable, representing a 44.3\% response rate. Among them, 107 were females $(60.5 \%)$ and 70 were males $(39.5 \%)$. In the questionnaire, bloggers evaluated the importance of the 10 blogging rewards $\left(A_{k}\right)$ to them (Table 2), and their perceived probability $\left(I_{k}\right)$ that blogging would like to produce on each of the 10 rewards (Table 3 ).

\section{<insert Table 2 here $>$ \\ <insert Table 3 here $>$}

\section{ANALYSIS AND RESULTS}

The research model was measured with the partial least squares (PLS) structural modeling analysis approach. PLS is appropriate for predicting highly complex models [3] and maximizing the variance explained for the constructs in a model [6]. Therefore, the research model was selected and tested with PLS.

\section{Measurement Model}

The measurement model was tested for estimated construct reliabilities, convergent validities and discriminant validity of instruments [2], [6], [12]. Table 4 presents the numbers of items, means, standard deviations and reliabilities of the constructs. All reliability measures were 0.7 or above. The alpha-level of the sample indicates a reasonable level of reliability $(\alpha>0.70)$ [15], revealing adequate internal consistency.

\section{<insert Table 4 here>}

Table 5 shows the each variable' the square root of AVE and intercorrelations, ranging from 0.242 to 0.581 . Convergent validity of the instrument is appropriate when the constructs have an average variance extracted (AVE) of at least 0.5 [11]. The square root of AVE should exceed the intercorrelations for satisfactory discriminant validity 
[2]. The AVE for every construct is larger than the correlation between the construct and other constructs in the model. Table 6 presents the factor loadings and cross-loadings of the items measured in this investigation. All items loadings of each construct are larger than cross-loadings of that construct with all other constructs. Hence, the convergent validity and discriminant validity in the work were adequate.

\section{<insert Table 5 here $>$ \\ <insert Table 6 here $>$}

\section{Structural Model}

The result of the structural model testing includes the path coefficients and the $\mathrm{R}^{2}$ values. The path coefficients denote the relationships between the dependent and independent constructs. The $\mathrm{R}^{2}$ values represent the degrees of variance explained by the independent constructs. Figure 2 illustrates the results of the structural model in this study. The research model explains variance in blogging intention $\left(\mathrm{R}^{2}=35.1 \%\right)$ and blogging conduct $\left(\mathrm{R}^{2}=7.8 \%\right)$. Motivation for blogging significantly influences blogging intention $(\beta=0.593, \mathrm{p}<0.01)$. Blogging intention is positively related to blogging conduct $(\beta=0.279, \mathrm{p}<0.01)$. Both hypotheses $\mathrm{H} 1$ and $\mathrm{H} 2$ are supported.

\section{<insert Figure 2 here $>$}

\section{CONCLUSIONS}

The analytical results of this investigation indicate the most important reward of extrinsic motivation is connecting with people who the blogger knows constantly. The most significant reward of intrinsic motivation is pouring out feelings on the blog and owning space to store blogger's data and file. Briefly, most bloggers on this study perceive the attractiveness or importance of intrinsic blogging rewards higher than those extrinsic rewards.

The highest probability of blogging productivity on achieving intrinsic rewards is to pour out blogger's feelings on the blog. The highest probability of achieving extrinsic rewards is the connecting with people who the blogger knows constantly. Inevitably, the bloggers weight the probability of blogging to achieve intrinsic rewards higher than the extrinsic rewards. Of the 10 motivations examined in this study, bloggers ranked pouring out feelings and connecting with people respectively, as their two most valued rewards. They also assigned the highest probabilities to these rewards. In another word, the two most important motivation factors for the bloggers to conduct blogging are the rewards of pouring out feelings and connecting with people.

In this study, expectancy theory [18] employed to examine the relationship between the motivation and the bloggers' intention and actual conducts. The collected data shows that bloggers with higher total (both intrinsic and extrinsic) motivation scores on rewards have higher level of blogging intention. A blogger with higher blogging intention is willing to take more time to operate and maintain their blog and post more articles on their blog.

The current research can lead to several further studies. First, the dependent construct here represents behavioral intention and conduct rather than actual performance of the blog (for example, number of visitors per day). It would be valuable that studies can be conducted to see whether the blogging conduct and the performance of blog are highly related to one another or not. A second concern is that the model tested here has been empirically assessed in only one conducting context. The gereralizability of the results reported here is not known beyond the current sample and blog conducting context. However, the proposed research model provides explanations and predictions to understand bloggers' behavior. Based on this understanding, system platform manager can determine what kinds of rewards can have the most meaningful impacts and how to improve the bloggers' intention and their conducts on operate their blogs.

\section{REFERENCES}

1. Andy Holloway. (2006). To blog, or not to blog? Canadian Business, 80(1), 15.

2. Barbara H Wixom, and Peter A Todd (2005). A Theoretical Integration of User Satisfaction and Technology Acceptance. Information Systems Research, 16(1), 85-102.

3. Barclay, D. W., C. A. Higgins, R. Thompson (1995). The Partial Least Squares (PLS) approach to causal modeling: Personal computer adoption and use as an illustration. Tech. Stud., 2(2), 285-309.

4. Bonnie A Nardi, Diane J Shiano, Michelle Gumbrecht, and Luke Swartz. (2004). Why we blog?. Communications of the ACM, 47(12), 4146.

5. Burton, F Greg, Chen, Yi-Ning, Grover, Varun, Stewart, and Kathy A. (1992-1993). An application of expectancy theory for assessing user motivation to utilize an expert system. Journal of Management Information Systems, 9(3), 183-198.

6. Christopher R. Plouffe, John S. Hulland, and 
Mark Vandenbosch (2001). Research report: richness versus parsimony in modeling technology adoption decisions - understanding merchant adoption of a smart card-based payment system. Information systems research, 12(2), 208-222.

7. Cynthia M. Jackson, Simeon Chow, and Robert A. Leitch. (1997). Toward an understanding of the behavioral intention to use an information system. Decision Sciences, 28(2), 357-388.

8. Davis, F. D., Bagozzi, R. P., \& Warshaw, P. R. (1989). User acceptance of computer technology: A comparison of two theoretical models. Management Science, 35(8), 982-1003.

9. Eva M Lang. (2005). Would you, could you, should you blog?. Journal of Accountancy, 199(6), 36-41.

10. Ferris, K. R. (1977). A test of the expectancy theory a motivation in an accounting environment. The Accounting Review, 52(3), 605-614.

11. Fornell, C., D. F. Larcker (1981). Evaluating structural equation models with unobservable variables and measurement error. Journal Marketing Research, 18, 39-50.

12. Hulland, J. (1999). Use of Partial Least Squares
(PLS) in strategic management research: A review of four recent studies. Strategic Management Journal, 20(2), 195-204.

13. Ji-Tsung Ben $\mathrm{Wu}$ and George $\mathrm{M}$ Marakas. (2006). The impact of operational user participation on perceived system implementation success: an empirical investigation. Journal of Computer Information Systems, 46(5), 127-140.

14. Judith Lamont (2007). Blogs and wikis: ready for prime time? KM World, 16(1), 2007, 14-17.

15. Nunnally, J. C. (1978). Psychometric Theory. McGraw-Hill, New York.

16. Rick Miller, (2007). It's time to get social-media savvy. PRweek, 10(13), 8.

17. Snead, Ken C, Harrell, and Adrian M. (1994). An application of expectancy theory to explain a manager's intention to use a decision support system. Decision Sciences, 25(4), 499-513.

18. Vroom, V. C. (1964). Work and motivation. New York: Wiley.

19. Yining Chen and Hao Lou. (2002). Toward an understanding of the behavioral intention to use a groupware application. Journal of End User Computing, 14(4), 1-15.

\section{TABLES AND FIGURES}

Table 1. Research Variables and Definitions Research Variables

Definition

$\begin{array}{ll}\text { Motivation for Blogging } & \begin{array}{l}\text { Overall Motivation of blogging is the summation of } \\ \text { multiplying the attractiveness of each reward by the } \\ \text { probability of its occurrence. }\end{array} \\ \text { Blogging Intention } & \begin{array}{l}\text { Degree to which a user intends to increases his use in the } \\ \text { future }\end{array} \\ \text { Blogging Conduct } & \begin{array}{l}\text { The number of posting articles and the time of } \\ \text { conducting the blog. }\end{array}\end{array}$

Table 2. Importance of Blogging Rewards to Blogger

\begin{tabular}{lcc}
\multicolumn{1}{c}{ Blogging Rewards } & Mean & Standard Deviation \\
\hline Intrinsic & & \\
Killing time with blogging & 8.0508 & 1.8958 \\
Having space to store my data and file & 8.3333 & 1.8361 \\
$\quad$ Enjoying sharing my life with others & 7.2655 & 1.8130 \\
$\quad$ Pouring out my feelings on my blog & 8.3955 & 1.6102 \\
$\quad$ Gaining achievement with blogging & 7.8079 & 1.9269 \\
Extrinsic & & \\
$\quad$ Looking forward to others' responses & 7.6328 & 1.8816 \\
$\quad$ Finding good topics when talking with others. & 7.9605 & 1.7560 \\
$\quad$ Connecting with people I know constantly & 8.5254 & 1.5524 \\
$\quad$ Knowing new friends. & 7.3729 & 1.8485 \\
Understanding others' feelings and opinions & 7.2486 & 2.0269
\end{tabular}


Table 3. Probability of Blogging Productivity on Achieving Various Rewards

\begin{tabular}{lcc}
\multicolumn{1}{c}{ Blogging Rewards } & Mean & Standard Deviation \\
\hline Intrinsic & & \\
Killing time with blogging & 7.0113 & 1.8555 \\
Having space to store my data and file & 7.3842 & 1.9245 \\
Enjoying sharing my life with others & 7.7062 & 1.7365 \\
Pouring out my feelings on my blog & 8.1864 & 1.6391 \\
$\quad$ Gaining achievement with blogging & 6.7966 & 1.8505 \\
Extrinsic & & \\
Looking forward to others' responses & 6.3164 & 2.0866 \\
Finding good topics when talking with others. & 6.5254 & 1.9888 \\
Connecting with people I know constantly & 7.6497 & 1.7259 \\
Knowing new friends. & 6.0113 & 2.1186 \\
Understanding others' feelings and opinions & 6.3390 & 2.1633
\end{tabular}

Table 4. Construct Means, Standard Deviations, and Reliabilities

\begin{tabular}{lcccc}
\multicolumn{1}{c}{ Construct } & $\begin{array}{c}\text { Number } \\
\text { of Items }\end{array}$ & Mean & $\begin{array}{c}\text { Standard } \\
\text { Deviation }\end{array}$ & $\begin{array}{c}\text { Cronbach } \\
\text { Alpha }\end{array}$ \\
\hline Motivation for blogging & 10 & 56.852 & 24.676 & 0.913 \\
Blogging Intention & 4 & 5.257 & 1.301 & 0.855 \\
Blogging Conduct & 2 & 2.376 & 0.892 & 0.708
\end{tabular}

Table 5. Correlations and Average Variance Extracted (AVE)

\begin{tabular}{lccc} 
& $\begin{array}{c}\text { Motivation for } \\
\text { Blogging }\end{array}$ & $\begin{array}{c}\text { Blogging } \\
\text { Intention }\end{array}$ & $\begin{array}{c}\text { Blogging } \\
\text { Conduct }\end{array}$ \\
\hline Motivation for blogging & $\mathbf{0 . 7 5 3}$ & & \\
Blogging Intention & $0.581^{* *}$ & $\mathbf{0 . 8 3 8}$ & \\
Blogging Conduct & $0.242^{* *}$ & $0.276^{* *}$ & $\mathbf{0 . 8 8 3}$
\end{tabular}

** Correlation is significant at the 0.01 level

Diagonal bolded elements are the square root of AVE.

Table 6. Factor Loadings and Cross-Loadings

\begin{tabular}{cccc} 
Items & $\begin{array}{c}\text { Motivation for } \\
\text { Blogging }\end{array}$ & $\begin{array}{c}\text { Blogging } \\
\text { Intention }\end{array}$ & $\begin{array}{c}\text { Blogging } \\
\text { Conduct }\end{array}$ \\
\hline Motivation for blogging & & & \\
Item 1 & $\mathbf{0 . 7 2 3 8}$ & 0.5029 & 0.1987 \\
Item 2 & $\mathbf{0 . 6 3 5 6}$ & 0.3720 & 0.1897 \\
Item 3 & $\mathbf{0 . 8 3 5 2}$ & 0.5289 & 0.3008 \\
Item 4 & $\mathbf{0 . 7 3 4 0}$ & 0.4028 & 0.2851 \\
Item 5 & $\mathbf{0 . 8 4 3 1}$ & 0.5213 & 0.1769 \\
Item 6 & $\mathbf{0 . 8 2 3 1}$ & 0.4864 & 0.1805 \\
Item 7 & $\mathbf{0 . 8 3 5 7}$ & 0.4704 & 0.1873 \\
Item 8 & $\mathbf{0 . 6 9 8 6}$ & 0.3834 & 0.1049 \\
Item 9 & $\mathbf{0 . 7 5 3 1}$ & 0.4136 & 0.1291 \\
Item 10 & $\mathbf{0 . 6 5 4 6}$ & 0.3464 & 0.0707 \\
Blogging Intention & & & \\
Item 1 & 0.4865 & $\mathbf{0 . 7 7 8 6}$ & 0.2260 \\
Item 2 & 0.5666 & $\mathbf{0 . 9 2 4 5}$ & 0.2766 \\
Item 3 & 0.5217 & $\mathbf{0 . 9 0 0 3}$ & 0.2418 \\
Item 4 & 0.4058 & $\mathbf{0 . 7 5 5 1}$ & 0.1862 \\
Blogging Conduct & & & \\
Item 1 & 0.2237 & 0.3015 & $\mathbf{0 . 9 1 2 2}$ \\
Item 2 & 0.2131 & 0.1837 & $\mathbf{0 . 8 6 3 0}$
\end{tabular}


Figure 1. The Research Model

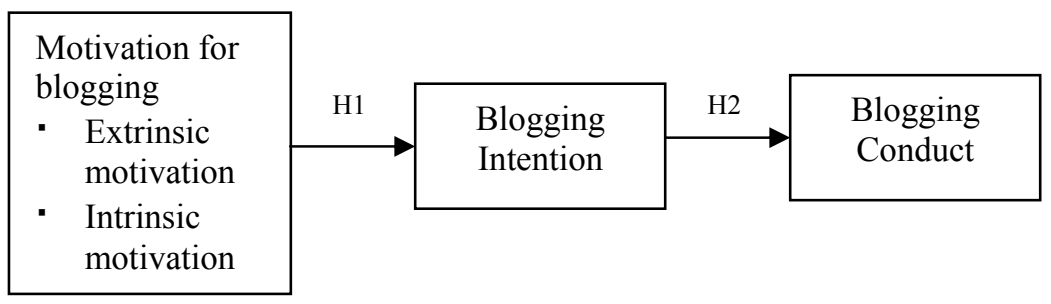

Figure 2. The Research Model Result

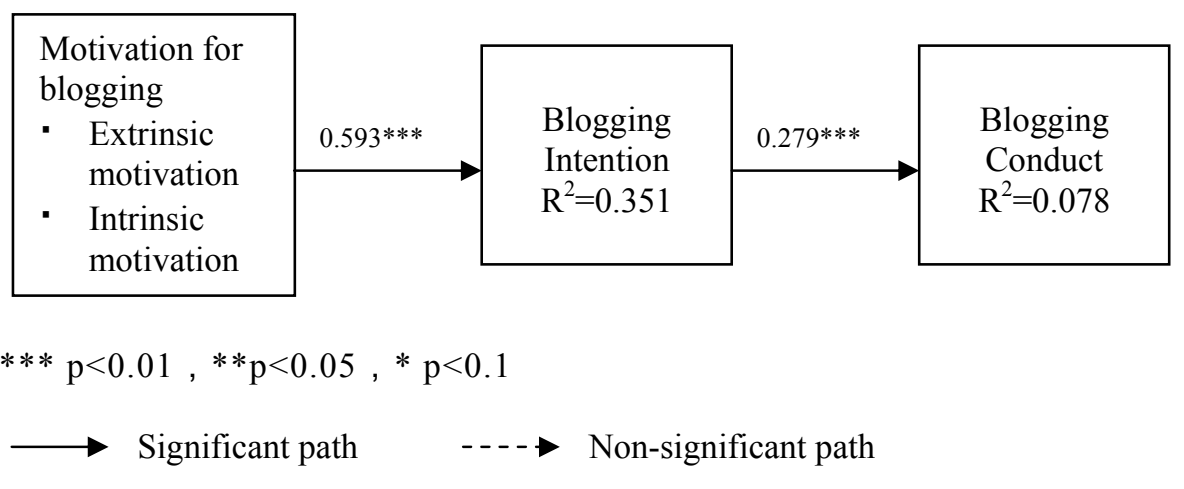

\section{APPENDIX : ITEMS AND SCALES}

\section{Intrinsic Blogging Rewards}

1. Killing time with blogging

2. Having space to store my data and file

3. Enjoying sharing my life with others

4. Pouring out my feelings on my blog

5. Gaining achievement with blogging

\section{Extrinsic Blogging Rewards}

1. Looking forward to others' responses

2. Finding good topics when talking with others.

3. Connecting with people I know constantly

4. Knowing new friends.

5. Understanding others' feelings and opinions

\section{Blogging Intention}

1. I intend to keep on conducting my blog in the future.

2. I intend to take more time to conduct my blog in the future.

3. I intend to conduct my blog frequently in the future.

4. I intend to recommend others to conduct their blogs.

\section{Blogging Conduct}

1. How many average articles do you publish on your blog every week?
$\square 0$
- 1-2
$\square$ 3-4
口 5-6
- 7 and above

2. How much average time do you take to conduct your blog every week?
- 1 hour below
$1 \sim 5$ hours
$\square$ above $5 \sim 10$ hours
$\square$ above 10 20 hours
- 20 hours above 